\title{
Morphologically Conservative but Physiologically Diverse: The Mode of Stasis in Anostraca (Crustacea: Branchiopoda)
}

\author{
Markus Lindholm
}

Received: 30 January 2014/ Accepted: 12 May 2014/Published online: 25 May 2014

(C) The Author(s) 2014. This article is published with open access at Springerlink.com

\begin{abstract}
The essay discusses whether biotic and abiotic environments differ in their ability to speed up or slow down morphological change and the generation of new lineages. Examples from the class Branchiopoda show that morphological conservatism is associated with enemy free space in species-poor habitats dominated by abiotic factors, while Red Queen mechanisms are predominant in larger systems with complex biotic interactions. Splitting of Branchiopod main lineages is associated with increased fish predation during the Devonian. The order Cladocera adapted and remained in larger aquatic systems, and subsequently generated a variety of new families, genera and species. The order Anostraca, on the other hand, maintained its ancestral morphology and survived only as "living fossils" in isolated ponds of harsh habitats. Despite their archaic morphology, however, they possess highly sophisticated adaptations to local physicochemical properties of their extreme environment. Hence, although morphologically conservative and possessing traits typical for "living fossils", anostracan physiological abilities are closely adapted to the challenging and variable physicochemical conditions of ponds and ephemeral pools.
\end{abstract}

Keywords Living fossils $\cdot$ Stasis $\cdot$ Pond $\cdot$ Anostraca . Branchinecta

M. Lindholm $(\bowtie)$

Norwegian Institute for Water Research/NIVA,

Gaustadalleen 23, 0349 Oslo, Norway

e-mail: Markus.Lindholm@niva.no

\section{Introduction}

Biological novelties become part of a population by means of natural selection, because factors in the environment that affect survival and reproduction favor specific adaptations. Many of these factors are themselves biological, in terms of parasites, symbionts, predators, prey or competitors. But even physicochemical conditions-UV radiation, temperature, drought, $\mathrm{pH}$, salinity or mechanical stress-evoke biological novelties. However, the evolutionary effects of abiotic factors on the one hand, and biological factors, on the other, may differ. Adaptive responses to the living environment tend to generate biological feedbacks, leading to continued fitness shifts in competing and mutually adapting lineages (Van Valen 1973; Stenseth and Maynard Smith 1984; Price 1988; Liow et al. 2011; Lawrence et al. 2012). The fine-tuned adjustments of inner organs in the animal body illustrate the principle, but it can be recognized wherever biotic factors have dominated the environment over geological time, such as rain forests or coral reefs. In fact, it has been claimed that most terrestrial novelties since the Cambrian arose in biotic, co-evolving environments (Price 2002; Benton 2009).

Similar dynamic feedback loops are less accentuated where adaptations relate to physical factors. Melanin does not alter the UV radiation regime, and thickening of leaf cuticle does not affect the tropical rain. Physical factors remain mainly unaffected by biological adaptations, making further adjustments less urgent (Butterfield 2007). Hence, while adaptations to biological agents possibly drive populations into nearly never-ending Red Queen dynamics, the corresponding morphological responses to physical factors are rather stagnant. Such differences could lead to different evolutionary histories and shed light on possible causes for the apparent imbalance between periods 
Fig. 1 Two primitive branchiopods, the Cambrian Rehbachiella kinnekullensis from Sweden (left), and Lepidocaris rhyniensis from the Devonian in Scotland (right) (drawings by K. Skilbrei)

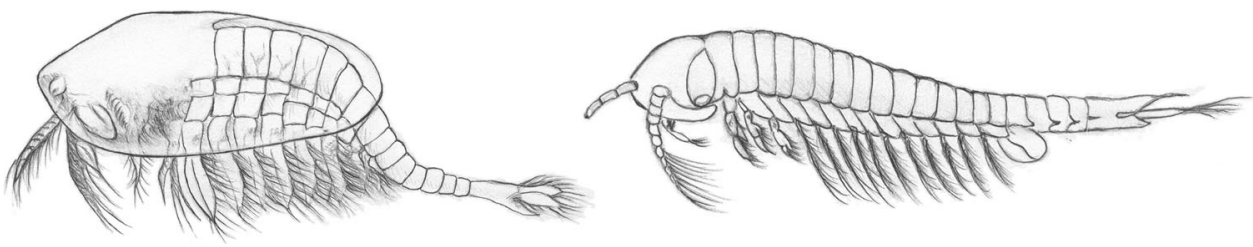

of morphological stasis and episodes of rapid lineage splitting (Eldredge et al. 2005; Hunt 2007).

This essay discusses if abiotic factors can help to explain morphological conservatism in certain crustaceans. Comparing two taxa of freshwater branchiopods, it explores how biological or physicochemical factors over geological time have driven lineages in different directions.

\section{The Origin of Branchiopods}

The class Branchiopoda comprises small to medium sized $(0.2-100 \mathrm{~mm})$ crustacean, primarily inhabiting freshwater. The taxon is rather small, amounting to 1,200 species worldwide, and molecular studies have settled their monophyletic origin (Richter et al. 2007). The class comprises ten orders, with Anostraca (fairy shrimps) and Cladocera (water fleas) as the most familiar. Their fossil record reaches back to the Paleozoic (Walossek 1998; Boxshall 2004), where the Anostraca is considered as the most ancient (Schram and Hof 1998). Their scattered, but worldwide distribution also points to a pre-Gondwanian origin. The oldest known anostracan fossil is Rehbachiella kinnekullensis from Swedish Cambrian rocks (Fig. 1, left). Their well preserved, leaf-like filtering appendages closely resemble those of recent descendants. Moreover, Harvey et al. (2012) reported well-preserved mandibles and filtering appendages of Cambrian branchiopods from Canada, nearly identical to those of recent anostracans. Another early species is the Devonian Lepidocaris rhyniensis from Scotland. Its segmented body and the lack of carapace are primitive characteristics even among recent fairy shrimps, and present juvenile stages closely resemble those of Lepidocaris, as well (Fig. 1, right). Altogether, these records suggest only weak morphological changes, and point to morphological conservatism as a main characteristic in the order Anostraca. Why was this ancient morphology maintained?

\section{The Community-Structuring Effects of Fish Predation}

A fateful event in the branchiopod history was the dawn of predatory fish, which accelerated during the Devonian, following fish novelties, such as fins, jaws and teeth

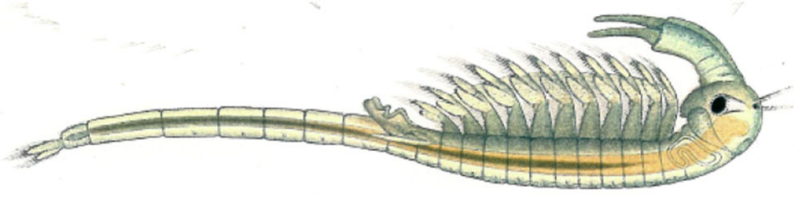

Fig. 2 The fairy shrimp Branchinecta paludosa (drawing by G.O. Sars)

(Wägele 1992; Rücklin et al. 2012). Aquatic invertebrates found themselves exposed to new and far more intense predation regimes. Cladoceran characteristics departed and diversified during the following period (Womack et al. 2012), in terms of life history, reproductive mode, body size and morphology. Firstly, they became so small that most fish fed on them only during the fry phase. The characteristic reproductive mode of cyclic parthenogenesis, moreover-a characteristic for many microcrustaceansallows high growth rates even when facing considerable predation pressures (Schmit et al. 2012). Recent forms also avoid visual predation by migration into deeper water layers at daytime, by increased transparency, or by formation of spines which make them less edible (Lindholm 2002; Laforsch and Tollrian 2004; Johnson et al. 2006). Their ability to co-exist with their principal predators allowed for various secondary adaptations, which made cladocerans the most diverse and successful taxon of all branchiopods (Adamovicz et al. 2009). The genus Daphnia evolved a suite of features associated with pelagic life, such as vertical tilting of the body axis and a pelagic driven, niche-partitioned and size-specific phytoplankton diet. Another successful lineage (Chydoridae) adapted to littoral microhabitats, or to floating particles on the water surface (Scapholeberis sp.). Some cladocerans returned to marine habitats (Evadne sp.), while others (Bythotrepes sp., Leptodora sp.) became predatory. Cladoceran ability to co-exist with fish hence opened up opportunities for numerous morphological novelties.

Anostracans responded different. Despite considerable size, they retained their archaic morphology. They still move slowly upside down through the open pelagial, filtering particles from the water, unable to hide in the bottom substrate, and hence an easy prey for fish (Fig. 2). The extreme rarity of coexistence between fairy shrimps and fish is consistent with this pattern, as are the detrimental 
effects of fish stocking on fairy shrimp populations (Eriksen and Belk 1999; Lindholm et al. 2012). Anostracan only survived in small, isolated habitats with peculiar features, and devoid of fish: shallow ponds and ephemeral pools, predominantly in inhospitable and extreme environments.

\section{Ponds and Ephemeral Pools are Harsh Habitats}

Ponds and pools possess features which in many respects differ profoundly from larger water bodies. Thermal structuring shelters most perennial lakes from meteorological extremes and facilitates stable conditions for temperature, oxygen, $\mathrm{pH}$ and nutrients. The biota is accordingly protected from sudden, steep physicochemical shifts (Jackson et al. 2001; Wetzel 2001). The stability contributes to niche separation and co-existence, and hydrological connectivity between lakes facilitates migration and higher biodiversity, as well (Oberdorff et al. 1997).

Ponds and ephemeral pools-rainwater filled depressions of warm-arid deserts, prairie potholes, volcanic mudflow pools, melt-water ponds in alpine or arctic environments or vernal pools in winter rain climates-are different. Most attempts to typify such water bodies have been based on physicochemical properties. Wiggins et al. (1980) emphasized the lack of hydrological connectivity between ponds and the dependence of true pond dwellers on dry resistant resting eggs to bridge desiccation periods. Williams (1985), working in semiarid environments, considered the degree of hydrological predictability and salinity as particularly important. Eng et al. (1990) classified three main groups of ponds, according to somewhat different variables: Episodic pools which fill and dry up repeatedly, perennial ponds, which exhibit large seasonal water level oscillations but rarely dry up, and aestival ponds, which are permanent, but shallow and freeze to the bottom during cold seasons. The latter classification circumscribes pond types inhabited by fairy shrimps.

The typology hides large local differences, though, and most ponds go through considerable seasonal shifts in physicochemical frame parameters (Eriksen and Belk 1999). Some become extremely clayish or saline, which cause strong fine-scaled thermal stratification (Eng et al. 1990). Others are clear and oscillate closely with atmospheric temperatures. Their unpredictable nature and rapid changes make aquatic vegetation poor, and size limits habitat diversity, as well. Most are rainwater fed (Williams 1985; Baskin 1994) or snowmelt driven (Lindholm et al. 2012) and, depending on local bedrock, accordingly prone to acidification. Some develop peculiar water chemistry, as in soda pans and seasonal salt lakes (Eng et al. 1990; Brandan et al. 1993). Extreme salinity, alkalinity, turbidity and $\mathrm{pH}$ are common in warm-arid regions (Gonzalez et al. 1996; Hebert et al. 2002), as is strong UV radiation (Sommaruga 2001; Marinone et al. 2006; Rautio et al. 2009) and rapid thermal oscillations in alpine and polar clear water pools (Peck 2005; van der Wal and Hessen 2009; Hegna and Lazo-Wasem 2010). Altogether, ephemeral ponds and pools belong to the most inhospitable and unpredictable habitats the earth, and, as might be expected, comprise impoverished diversity and comparatively poor biotic interactions (De Meester et al. 2005; Ripley and Simovich 2009). Some insects, such as Dytiscides and Notonectids, may exploit resources of ephemeral pools. A number of crustacean, notably ostracods, cladoceran and copepods, inhabit pools and ponds, as well. But fairy shrimps have limited their occurrence entirely to these extreme habitats.

\section{Morphologically Conservative but Physiologically Diverse}

The emerging pattern is hence evolutionary lineages rather exposed to physicochemical than to biotic stressors. Sheltered from competition and predation, fairy shrimps managed to maintain their archaic morphology and behavior. Instead of getting entangled in Red Queen dynamics, they ended up as "fugitive species" (Hutchinson 1951) in largely enemy-free habitats, devoid not only of fish, but also of other potential competitors or invertebrate predators (Hurlbert et al. 1986). The pools and ponds instead demanded peculiar physiological abilities, in order to cope with the rapid local changes in physicochemical frames, or with permanent extreme conditions.

A closer look at the large and widespread anostracan genus Branchinecta may illustrate this point. In arid California, B. lindahli starts its life in rainwater pools at temperatures close to zero, which however approaches $35{ }^{\circ} \mathrm{C}$ during summer (Eriksen and Belk 1999). In Antarctic melt water pools, B. gaini is exposed to diurnal temperature oscillations amounting to $25^{\circ} \mathrm{C}$ (Peck 2005). Alpine ponds in higher latitudes of Europe, where $B$. paludosa hatches at snow melt, also regularly reach $25{ }^{\circ} \mathrm{C}$ after few weeks (pers.obs.). Until recently were the plentiful vernal pools in the southeastern European steppe region inhabited by $B$. ferox, but these habitats are now mainly extinct. A number of species persist in seasonal ponds where salt levels exceed that of sea water during the last period before dry up (Alonso 1990; Brandan et al. 1993). Other Branchinectids are adapted to permanent extreme conditions. In the Andes, B. brushi inhabits clearwater pools close to 6,000 m.a.s.l., with strong UV loads (Hegna and Lazo-Wasem 2010). And chlorinated and sulphated ponds in the neighboring Atacama Desert are 
preferred habitats for B. papillata (Rogers et al. 2008). Other species, such as $B$. lindahli, has adapted to extreme alkaline water, with $\mathrm{pH}$ approaching 10 (Eng et al. 1990). Hence, although morphological conservative are fairy shrimps physiologically highly diverse, and in part also highly flexible in facing steep physicochemical shifts.

The combination of morphological conservatism and physiological flexibility found in many anostracan has much in common with the findings of Wake et al. (1983), who argued that morphological stasis in the salamander family Plethodontidae was intimately connected to their unusual flexible behavior. It also relates to Sheldon's (1996) concept of stasis in rapid fluctuating environments. While environments dominated by biological interactions counteract physical fluctuations and promote niche separation and lineage splitting, could fluctuating physicochemical stressors favor flexibility, as "selection soon tends to favor lineages with "all-purpose" hardpart morphologies that are relatively inert to each environmental twist and turn" (Sheldon 1996, p. 213). Physiological generalists gain increased fitness in temporally heterogeneous habitats, which enable them to cope, and not to adapt, with periods of extremes. Relations between morphological conservatism and fluctuating environments are reported for other crustaceans, as well. A large scale example is the Pleistocene glaciation, which failed to cause enhanced speciation rates. Lineage conservatism during Pleistocene at northern latitudes is documented for a range of taxa, including vascular plants (Willis and Niklas 2004), insects (Coope 2004), marine invertebrates (Jackson and Sheldon 1994), birds (Zink et al. 2004) and mammals (Barnosky 2005).

Two very different realms-morphology and physiology-meet in every living being. The history of Branchiopods signals that the two not always go along identical evolutionary pathways. Following the advent of predatory fish of the Devonian, cladoceran adapted a broad suite of morphological and life history traits which allowed coexistence and complex Red Queen dynamics with competitors and predators. Anostracan, on the other, never solved the problem of coexistence with their principal predators, and found themselves marginalized to enemy free habitats in extreme environments, where they remained morphologically unaltered, but purified the adaptive interface between their physicochemical environment and their internal physiology.

Open Access This article is distributed under the terms of the Creative Commons Attribution License which permits any use, distribution, and reproduction in any medium, provided the original author(s) and the source are credited.

\section{References}

Adamovicz, S. J., Petrusek, A., Colbourne, J. K., Hebert, P. N. J., \& Witt, J. D. S. (2009). The scale of divergence: A phylogenetic appraisal of intercontinental allopatric speciation in a passively dispersed freshwater zooplankton genus. Molecular Phylogenetics and Evolution, 50, 423-436.

Alonso, M. (1990). Anostraca, Cladocera and Copepoda of Spanish saline lakes. Hydrobiologia, 197, 221-231.

Barnosky, A. D. (2005). Effects of quaternary climatic change on speciation in mammals. Journal of Mammalian Evolution, 12, 247-264.

Baskin, Y. (1994). California's ephemeral vernal pools may be a good model for speciation. Biosience, 44(6), 384-388.

Benton, M. J. (2009). The red queen and the court jester: species diversity and the role of biotic and abiotic factors through time. Science, 323, 728-732.

Boxshall, G. A. (2004). The evolution of arthropod limbs. Biological Reviews, 79, 253-300.

Brandan, E., Urrea, R., \& Gajardo, G. (1993). Effect of salt concentration on the synthesis of suphated macromolecules in the brine shrimp (Artemia franciscana) - Changes of sulfation rate during development. Comparative Biochemistry and Physiology A-Physiology, 105(3), 519-523.

Butterfield, N. J. (2007). Macroevolution and macroecology through deep time. Paleontology, 50(1), 41-55.

Coope, G. R. (2004). Several million years of stability among insect species because of, or in spite of, Ice Age climatic instability? Philosophic Transactions of the Royal Society of London Series B, 359, 209-214.

De Meester, L., Declerck, S., Stoks, R., Lorette, G., Van De Meutter, F., De Bie, T., et al. (2005). Ponds and pools as model systems in conservation biology, ecology and evolutionary biology. Aquatic Conservation: Marine and Freshwater Ecosystems, 15, 715-725.

Eldredge, N., Thompson, J. N., Brakefield, P. M., et al. (2005). The dynamics of evolutionary stasis. Paleobiology, 31, 133-145.

Eng, L. L., Belk, D., \& Eriksen, C. H. (1990). Californian Anostraca: Distribution, habitat and status. Journal of Crustacean Biology, 10, 247-277.

Eriksen, C. H., \& Belk, D. (1999). Fairy shrimps of California's puddles, pools and playas. Eureka, CA: Mad River Press.

Gonzalez, R. J., Drazen, J., Hathaway, S., Bauer, B., \& Simovich, M. (1996). Physiological correlates of water chemistry requirements in fairy shrimps (Anostraca) from Southern California. Journal of Crustaceal Biology, 16, 286-293.

Harvey, T. H. P., Velez, M. I., \& Butterfield, N. J. (2012). Exceptionally preserved crustaceans from western Canada reveal a cryptic Cambrian radiation. Proceedings of the National Academy of Science, 109, 1589-1594.

Hebert, P. D. N., Remigio, E. A., Colbourne, J. K., Taylor, D. J., \& Wilson, C. C. (2002). Accelerated molecular evolution in halophilic crustacean. Evolution, 56(5), 909-926.

Hegna, T. A., \& Lazo-Wasem, E. A. (2010). Branchinecta brushi n. sp. (Branchiopoda: Anostraca: Branchinectidae) from a volcanic crater in northern Chile (Antofagasta Province): A new altitude record for crustaceans. Journal of Crustacean Biology, 303, $445-464$.

Hunt, G. (2007). The relative importance of directional change, random walk, and stasis in the evolution of fossil lineages. Proceedings of the National Academy of Science, 104, 18404-18408.

Hurlbert, S., Loayza, W., \& Moreno, T. (1986). Fish-flamingoplankton interactions in the Peruvian Andes. Limnology and Oceanography, 31(3), 457-468. 
Hutchinson, G. E. (1951). Copepodology for the ornithologist. Ecology, 32, 571-577.

Jackson, D. A., Peres-Neto, P. R., \& Olden, J. D. (2001). What controls who is where in freshwater fish communities-the roles of biotic, abiotic, and spatial factors. Canadian Journal for Fisheries and Aquatic Science, 58, 157-170.

Jackson, J. B. C., \& Sheldon, P. R. (1994). Constancy and change of life in the Sea. Philosophical Transactions of the Royal Society of London. Series B, 344(1307), 55-60.

Johnson, P. T. J., Stanton, D. E., Preu, E. R., Forshay, K. J., \& Carpenter, S. R. (2006). Dining on disease: How interactions between infection and environment affect predation risk. Ecology, 87, 1973-1980.

Laforsch, C., \& Tollrian, R. (2004). Inducible defenses in multipredator environments: Cyclomorphosis in Daphnia cucullata. Ecology, 85, 2302-2311.

Lawrence, D., Fiegna, F., Behrends, V., Bundy, J. G., Phillimore, A. B., Bell, T., et al. (2012). Species interactions alter evolutionary responses to a novel environment. PLoS Biology, 10(5), e1001330. doi:10.1371/journal.pbio.1001330.

Lindholm, M. (2002). Predator-induced cyclomorphosis in Daphnia laevis from a tropical floodplain (Okavango Delta, Botswana). Crustaceana, 75, 803-814.

Lindholm, M., Stordal, F., Hessen, D. O., Moe, S. J., \& Aass, P. (2012). Climate driven range retraction of an Arctic freshwater crustacean. Freshwater Biology, 57, 2591-2601.

Liow, L. H., Van Valen, L., \& Stenseth, N. C. (2011). Red queen: From populations to taxa and communities. Trends in Ecology \& Evolution, 26(7), 349-358.

Marinone, M. C., Marque, S. M., Suarez, D. A., Diéguez Mdel, C., Pérez, P., De Los Ríos, P., et al. (2006). UV radiation as a potential driving force for zooplankton community structure in Patagonian Lakes. Photochemistry and Photobiology, 82, 962-971.

Oberdorff, T., Hugueny, B., \& Gueran, J.-F. (1997). Is there an influence of historical events on contemporary fish species richness in rivers? Comparisons between Western Europe and North America. Journal of Biogeography, 24, 461-467.

Peck, L. S. (2005). Prospects for surviving climate change in Antarctic aquatic species. Frontiers in Zoology, 2, 9.

Price, P. W. (1988). An overview of organismal interactions in ecosystems in evolutionary and ecological time. Agriculture, Ecosystems \& Environment, 24, 369-377.

Price, P. W. (2002). Species interactions and the evolution of biodiversity. In O. Pellmyr \& C. Herrera (Eds.), Plant-animal interactions (pp. 3-26). Oxford: Blackwell Science.

Rautio, M., Bonilla, S., \& Vincent, W. F. (2009). UV photoprotectants in Arctic zooplankton. Aquatic Biology, 7, 93-105.

Richter, S., Olesen, J., \& Weeler, W. C. (2007). Phylogeny of Branchiopoda (Crustacea) based on a combined analysis of morphological data and six molecular loci. Cladistics, 23, 301-336.

Ripley, B. J., \& Simovich, M. A. (2009). Species richness on islands in time: Variation in ephemeral pond crustacean communities in relation to habitat duration and size. Hydrobiologia, 617, 181-196.

Rogers, D. C., los Rios, P. D., \& Zuniga, O. (2008). Fairy shrimp (Branchiopoda: Anostraca) of Chile. Journal of Crustacean Biology, 28, 543-550.
Rücklin, M., Donoghue, P. C. J., Johanson, Z., Trinajstic, K., Marone, F., \& Stampanoni, M. (2012). Development of teeth and jaws in the earliest jawed vertebrates. Nature, 491, 748-751.

Schmit, O., Martens, K., \& Mesquita-Joanes, F. (2012). Vulnerability of sexual and asexual Eucypris virens (Crustacea, Ostracoda) to predation: An experimental approach with dragonfly naiads. Fundamental and Applied Limnology, 181(3), 207-214.

Schram, F. R., \& Hof, C. J. H. (1998). Fossils and the interrelationship of major crustacean groups. In G. D. Edgecombe (Ed.), Arthropod fossils and phylogeny (pp. 233-302). New York: Colombia University Press.

Sheldon, P. R. (1996). Plus ca change-a model for stasis and evolution in different environments. Palaeogeography, Palaeoclimatology, Palaeoecology, 127, 209-227.

Sommaruga, R. (2001). The role of solar UV radiation in the ecology of alpine lakes. Journal of Photochemistry and Photobiology B: Biology, 62, 35-42.

Stenseth, N. C., \& Maynard Smith, J. (1984). Coevolution in ecosystems: Red queen evolution or stasis? Evolution, 38, 870-880.

van der Wal, R., \& Hessen, D. O. (2009). Analogous aquatic and terrestrial food webs in the high Arctic: The structuring force of a harsh climate. Perspectives in Plant Ecology, Evolution and Systematics. doi:10.1016/j.ppees.2009.03.003.

Van Valen, L. (1973). A new evolutionary law. Evolutionary Theory, $1,1-30$.

Wägele, J. W. (1992). Co-evolution between fishes and crustacean. Acta Zoologica, 73, 355-356.

Wake, D. B., Roth, G., \& Wake, M. H. (1983). On the problem of stasis in organismal evolution. Journal of Theoretical Biology, 101, 211-224.

Walossek, D. (1998). On the Cambrian diversity of Crustacea. In F. R. Schram \& J. C. von Naupel Klein (Eds.), Crustaceans and the biodiversity crisis. Proceedings of the Fourth International Crustacean Congress, Amsterdam, The Netherlands July 20-24, vol. 1. Brill Academic, Leiden.

Wetzel, R. G. (2001). Limnology Lake and river ecosystems. San Diego: Elsevier.

Wiggins, G. B., Mackay, R. J., \& Smith, I. M. (1980). Evolutionary and ecological strategies of animals in annual temporary pools. Archiv für Hydrobiologie Supplement, 58, 97-206.

Williams, W. D. (1985). Biotic adaptations in temporary lentic waters, with special references to those in semi-arid and arid regions. Hydrobiologia, 125, 85-110.

Willis, K. J., \& Niklas, K. J. (2004). The role of quaternary environmental change in plant macroevolution: The exception or the rule? Philosophical Transactions of the Royal Society of London. Series B, 359, 159-172.

Womack, T., Slater, B. J., Stevens, L. G., Anderson, L. I., \& Hilton, J. (2012). First cladoceran fossils from the carboniferous: Palaeoenvironmental and evolutionary implications. Palaeogeography, Palaeoclimatology, Palaeoecology, 344-345, 39-48.

Zink, R. M., Klicka, J., \& Barber, B. R. (2004). The tempo of avian diversification during the quaternary. Philosophical Transactions of the Royal Society of London. Series B, 359, 215-220. 